\title{
PESQUISA INTERINSTITUCIONAL EM PARCEIRA: um espaço de possibilidades formativas
}

\author{
Research interinstitucional in partner: \\ a space of formative possibilities
}

\author{
Ilma Passos Alencastro Veiga \\ Professora Titular da Universidade de Brasília, Brasília, DF - Brasil, e-mail: \\ ipaveiga@ terra.com.br
}

\section{Resumo}

A pesquisa em educação, especialmente a pesquisa interinstitucional, é uma proposta metodológica em construção e, possivelmente, continuará assim. 0 principal motivo que me levou a perseguir 0 objetivo de discutir e clarear algumas questões referentes à pesquisa interinstitucional foi a preocupação que vem incomodando investigadores e professores que decidiram desenvolver projetos em parcerias envolvendo duas ou mais instituições universitárias. Neste texto, procuro realizar um mapeamento do significado e características fundamentais, identificar algumas lições aprendidas, apresentar seus limites e possibilidades inovadoras para a formação de professoresinvestigadores. O s grupos de pesquisa interinstitucionais, dependendo de seus interesses, se identificam pela possibilidade de compartilhar problemas, experiências e objetivos comuns. A pesquisa interinstitucional entre professores-pesquisadores e alunos de diferentes instituições de educação superior tem surgido como resposta às transformações sociais, políticas, culturais e tecnológicas que colocam em discussão as formas conservadoras e individualistas de produção de conhecimento e desenvolvimento profissional de

Rev. D iálogo Educ., Curitiba, v. 9, n. 26, p. 47-59, jan./ abr. 2009 
professores. As características fundamentais da pesquisa interinstitucional são: trabalho coletivo; 0 comum se constrói pelas diferenças; fortalecimento do papel do pesquisador e dos pesquisados; construção de rede ao longo do processo. 0 processo investigativo é rico em experiências.

Palavras-chave: Formação de professores. Educação superior. Pesquisa.

\begin{abstract}
Research in Education, especially inter-institutional research, is a methodological proposition in construction, and it will possibly continue to be such. The main reason for me to pursue this goal of discussing and clarifying some issues related to inter-institutional research has been the concern of researchers and teachers who are developing projects in partnership involving two or more university institutions. In this paper, I try to map the meaning and fundamental features of this kind of research, to identify some lessons that have been learned, and to present limits and innovative possibilities of inter-institutional research for teacher-researcher training. The inter-institutional groups of research, according to their interests, can find a common ground in the possibility of sharing similar problems, experiences and goals. The interinstitutional research involving professors-researchers and students of different university institutions is arising as an answer to social, political, cultural and technological transformations which call into question conservative and individualistic forms of knowledge production and of teachers' professional development. The fundamental features of inter-institutional research are: collective work; a common ground built through the differences; strengthening of the role of investigators and people investigated; a network construction along the process. The research process is rich in experiences.
\end{abstract}

Keywords: Teacher training. Superior degree instruction. Research.

Rev. Diálogo Educ., Curitiba, v. 9, n. 26, p. 47-59, jan./ abr. 2009 
Muito deste texto constitui um arranjo de ideias baseadas em vários autores e de vivências calcadas em grupos coletivos de pesquisa interinstitucional. Minha primeira experiência de investigação em parceria envolvendo várias universidades foi no momento em que participei do projeto Inovação como fator de revitalização do ensinar e do aprender na U niversidade. Essa pesquisa, desenvolvida em quatro Universidades (UFRG S, UFPel, UnB e UBA, na Argentina) mostrou que o próprio fato de construir a parceria constitui um horizonte de inovação. Isso permitiu compreender que a investigação interinstitucional busca, além de produzir conhecimento coletivamente, construir uma outra possibilidade do trabalho de pesquisa em grupo distante da lógica dominante e que pressupõe ir além da racionalidade cognitivo-instrumental, sobrepondo-lhe outras racionalidades, como a cognitivo-afetiva e a estético-expressiva (SANTOS, 1989, 1994).

A segunda experiência foi uma pesquisa sobre a formação de profissionais de educação intitulada L icenciatura em Pedagogia: realidades, incertezas, utopias. Essa investigação foi também desenvolvida em quatro universidades federais localizadas em Estados distintos (UnB, UFU, UFMS e UFPel). Para enfrentar tal processo investigativo, foi necessário formar grupos interinstitucionais. Embora de lugares e projetos de cursos diferentes, todos trabalharam juntos. 0 estudo evidenciou que as reflexões e debates foram bastante ricos e propositivos. Houve uma aprendizagem compartilhada tanto em relação à produção de conhecimento quanto ao desenvolvimento profissional do grupo de pesquisadores interinstitucionais.

A terceira experiência de pesquisa em parceria girou em torno de um tema maior de interesse do grupo com um único problema, ou seja, a construção ético-profissional da docência. A constituição de um grupo de pesquisa sobre esse tema, com pesquisadores de três instituições universitárias (UnB, UFU e UNITRI), muito contribuiu para ampliar a compreensão de pesquisa interinstitucional em parceria.

A quarta experiência é com 0 projeto D ocência universitária e desenvolvimento profissional, uma parceria entre a Universidade de Brasília e a Universidade Federal de Uberlândia. Essa pesquisa, em andamento, objetiva compreender o desenvolvimento profissional dos docentes universitários, visando desvelar significados e sentidos que compõem seus saberes e suas práticas educativas. Seus resultados parciais têm proporcionado uma visão mais abrangente da temática e a compreensão de que o conhecimento é uma produção gradativa de um coletivo pensante, como enfatiza Lévy (1999).

Uma quinta experiência iniciada em 2004 está ligada ao projeto interinstitucional denominado A D idática e a formação de professores para a educação básica e superior, congregando pesquisadores de duas universidades públicas, a Universidade de Brasília (UnB) e a Universidade Federal de Uberlândia (UFU), e

Rev. D iálogo Educ., Curitiba, v. 9, n. 26, p. 47-59, jan./ abr. 2009 
uma instituição privada, o Centro Universitário de Brasília (UniCEUB), com 0 objetivo de configurar a educação superior como importante campo de produção do conhecimento sobre formação de professores.

A pesquisa em educação, especialmente a pesquisa interinstitucional, é uma proposta metodológica em construção e possivelmente continuará assim. O principal motivo que me levou a perseguir o objetivo de discutir e clarear algumas questões referentes à pesquisa interinstitucional foi a preocupação que vem incomodando alguns investigadores decididos a desenvolver projetos em parceria, envolvendo duas ou mais instituições universitárias.

Neste texto, procuro realizar inicialmente um mapeamento do significado e características fundamentais e modalidades da pesquisa interinstitucional. Em seguida, identifico algumas lições aprendidas ao longo dos processos investigativos vivenciados, apresentando seus limites e possibilidades inovadoras.

\section{0 significado de pesquisa interinstitucional}

Etimologicamente, pesquisa é o ato de pesquisar e significa "investigação e estudo, minudentes e sistemáticos, com o fim de descobrir ou estabelecer fatos ou princípios relativos a um campo qualquer de conhecimento." (FERREIRA, 1999, p. 1556). Investigar com o fim de descobrir fatos ou princípios relativos a um campo do conhecimento. Houaiss (2001, p. 2200) afirma que "pesquisa é o conjunto de atividades que têm por finalidade a descoberta de novos conhecimentos no domínio científico, literário, artístico etc. Investigação ou indagação minuciosa. Exame de laboratório."

A pesquisa interinstitucional implica reciprocidade, pois realiza-se entre instituições universitárias. 0 prefixo inter evidencia uma posição intermediária e recíproca. Assim, a pesquisa interinstitucional envolve o trabalho em grupo, a parceria, a colaboração. É um processo coletivo de colaboração entre grupos. 0 trabalho investigativo é coletivo, e isto significa ação conjunta de investigação, de indagação pormenorizada.

Pesquisa interinstitucional, em seu sentido etimológico, significa inventar, romper, conviver com a reciprocidade, com o coletivo, incorporados numa mesma dimensão de trabalho.

Por outro lado, a expressão pesquisa interinstitucional é utilizada num sentido formal, para referir-se a uma categoria de investigação orientada pelos órgãos de financiamento como é o caso do Conselho Nacional de D esenvolvimento Científico e Tecnológico - CNPq. Neste sentido, os grupos de pesquisa são constituídos para a produção do conhecimento em parceria.

Rev. Diálogo Educ., Curitiba, v. 9, n. 26, p. 47-59, jan./ abr. 2009 
Os grupos interinstitucionais de pesquisa, dependendo de seus interesses, identificam-se pela possibilidade de compartilhar problemas, experiências e objetivos comuns. A pesquisa interinstitucional entre professorespesquisadores e alunos de diferentes instituições de educação superior tem surgido como resposta às transformações sociais, políticas, culturais e tecnológicas que colocam em discussão as formas conservadoras e individualistas de produção de conhecimento e desenvolvimento profissional de professores.

O liveira (1986, p. 67) enfatiza que a pesquisa em grupo, no âmbito universitário, pode ser reunida em três tipos:

a) no primeiro - agregação: as pesquisas e os temas não têm interdependência, "qualquer semelhança não passa de mera coincidência." Esse tipo de organização visa atender aos órgãos de fomento e financiamento de pesquisa;

b) no segundo - linhas de pesquisa: são próprias da estrutura curricular dos Programas de Pós-Graduação em Educação e constituídas como foco de avaliação da Coordenação de A perfeiçoamento de Pessoal de Nível Superior (CAPES). Para O liveira "só muito raramente as linhas de pesquisa correspondem a uma real interação intelectual entre os membros de um mesmo departamento";

c) no terceiro - atividades interdisciplinares: os interesses, nessa forma de integração, estão aglutinados em torno de uma questão norteadora ou de uma metodologia e propiciariam a integração entre pesquisadores de diferentes áreas do conhecimento.

A construção da pesquisa em parceria, na perspectiva da integração, "[...] não se resume a um mesmo tempo, espaço e território. Ela se dá em diferentes espaços interinstitucionais com pesquisadores de distintas qualificações." (LEITE et al., 1999, p. 48).

Os pesquisadores interinstitucionais não são meros auxiliares ou coletores de informações e materiais diversos; são sujeitos que não apenas desenvolvem, mas também constroem profissionalmente conhecimentos, realizam trocas de experiências. González Rey (2002, p. 57) afirma com muita convicção que:

[...] 0 pesquisador e suas relações com o sujeito pesquisado são os principais protagonistas da pesquisa, e os instrumentos deixam o lugar de protagonistas. D e sua parte, o pesquisado adquire um papel essencial; no entanto,

Rev. D iálogo Educ., Curitiba, v. 9, n. 26, p. 47-59, jan./ abr. 2009 
não representa uma entidade objetiva, homogeneizada pelo tipo de resposta que deve dar, mas é reconhecido em sua singularidade como responsável pela qualidade de sua expressão, relacionada com a qualidade de seu vínculo com o pesquisador.

Nesse sentido, o grupo de pesquisa interinstitucional não é uma simples justaposição dos sujeitos, mas representa a síntese das interlocuções entre os pesquisadores e os sujeitos pesquisados. A esse respeito, D emo (1996, p. 18) afirma - com muita propriedade - que trabalhar em equipe é:

[...] um reclamo cada vez mais insistente dos tempos modernos, por várias razões muito convincentes. D e uma parte trata-se de superar a especialização excessiva, que sabe muito de quase nada, portanto não faz jus à complexidade da realidade, seus problemas e desafios, de modo matricial, globalizado, multidisciplinar. De outra, 0 trabalho de equipe, além de ressaltar o repto da competência formal, coloca a necessidade de exercitar a cidadania coletiva e organizada, à medida que se torna crucial argumentar na direção dos consensos possíveis.

Isto desmistifica a pesquisa como uma ação invariavelmente complexa e solitária, destinada a alguns iluminadamente privilegiados. 0 trabalho investigativo em grupo, em parceria e interinstitucional deve abrir espaço para a ação solidária. É na relação com o outro como sujeito que o indivíduo "[...] deixa de ser um elemento de funcionamento do sistema social e se torna criador de si mesmo e produtor da sociedade". (TO URAINE, 1999, p. 240). Se de um lado, é preciso aprender a ver o outro como sujeito, por outro, é preciso aprender a ouvilo pois, como afirma Freire (1998, p. 127), "[...] somente quem escuta paciente e criticamente o outro, fala com ele". (G rifo do autor). O uvir atentamente a expressão dos sentimentos profundos, numa atitude de aceitação, dando atenção às diferentes vozes. A postura de ser ouvido é o que permite ao outro expressarse como outro, abrindo o espaço que facilita o falar. Por isso é que Freire acrescenta: "[...] quem tem o que dizer deve assumir o dever de motivar, de desafiar quem escuta, no sentido de que quem escuta diga, fale, responda" (FREIRE, 1998, p. 132). (G rifo do autor).

A busca do entendimento comum tem relação com a construção do sentimento de pertença e de compromisso compartilhados com o projeto de investigação eo trabalho do grupo. Háparceria quando todos trabalham conjuntamente e se apoiam mutuamente, visando atingir objetivos comuns negociados pelo coletivo

Rev. Diálogo Educ., Curitiba, v. 9, n. 26, p. 47-59, jan./ abr. 2009 
do grupo. Há vontade de querer trabalhar junto com os outros pesquisadores e de outras instituições como grupo social, de desejar fazer parte de um determinado grupo, sem imposição ou cooptação. Implica a articulação de diferentes níveis e modalidades de atuação. Há necessidade de criar espaços que estimulem e propiciem diferentes ações que se articulam em torno de objetivos comuns.

A finalidade de um projeto interinstitucional deve resultar do entendimento mútuo de todos os pesquisadores. Assim, todo o processo investigativo - definição e delimitação do problema, construção do referencial teórico-metodológico, bem como coleta, análise e interpretação dos dados - deve ser decidido e assumido coletivamente pelos pesquisadores. Vale ressaltar que também a redação e autoria do relatório final sejam compartilhadas. Todos assumem a responsabilidade de cumprir e fazer cumprir os acertos grupais, tendo em vista seus objetivos comuns, a concepção do projeto de estudo, os acordos com relação ao cronograma de atividades e a responsabilidade de cada pesquisador para o desenvolvimento interinstitucional da pesquisa. Esse tipo de pesquisa que se apoia na participação e na colaboração no sentido de trabalhar conjuntamente a partir de objetivos comuns "há de ter um sentido para os participantes, sem 0 qual é pouco provável que se produza o tipo de informação de que necessitamos" (GONZÁLEZ REY, 2002, p. 59).

A pesquisa interinstitucional em parceria opõe-se à concepção de que o coletivo resulta do consenso. Aponta para a compreensão e o enfrentamento das contradições internas e externas ao processo investigativo como forma de aprofundamento e superação dos conflitos e tensões. Portanto, implica relação contratual, isto é, um acatamento do projeto por todos os envolvidos.

Converte-se, então, em espaço aberto ao diálogo e interações entre os pesquisadores e os sujeitos pesquisados das diferentes instituições educativas. Em síntese, pesquisar é produzir conhecimento novo que deve ser referendado pelos professores, pesquisadores e alunos.

\section{Características fundamentais e modalidades da pesquisa interinstitucional}

Apresentei, no item anterior, os significados de pesquisa sob os pontos de vista etimológico eformal. N este item, procuro destacar as características fundamentais e as modalidades da pesquisa interinstitucional.

A primeira dessas características diz respeito ao trabalho coletivo calcado no caráter integrador da ação investigativa. A aproximação do grupo de pesquisa dá-se pela temática de interesse comum, o que possibilita a investigação em uma perspectiva de construção coletiva. Essa possibilidade de interação entre

Rev. D iálogo Educ., Curitiba, v. 9, n. 26, p. 47-59, jan./ abr. 2009 
os pesquisadores do grupo fomenta - de maneira geral - respostas mais ricas, inovadoras, contribuindo para a produção do conhecimento. Refletir coletivamente uma temática que faz parte das preocupações da vida acadêmica éo eixo norteador e integrador do processo investigativo.

A segunda característica está alicerçada no enunciado de que "0 comum se constrói pelas diferenças" (LEITE et al., 1999, p. 49). A pesquisa interinstitucional envolve uma parceria com diferentes grupos de pesquisa de diferentes instituições de educação superior, em diferentes localidades e diferentes esferas administrativas. Para os autores, a aproximação dos diferentes dá-se num processo de atração e repulsão.

0 que aproxima e atrai diferentes grupos de pesquisa de diferentes instituições são as deficiências, necessidades, inquietações, descontentamentos, entre outros que têm em comum a ponto de agrupá-los numa perspectiva coletiva. A repulsão se dá pelo

[...] sentimento comum contra o egoísmo da propriedade intelectual que se desdobra nas individualidades que tentam sobrepor-se às outras e contra a luta concorrencial dentro do campo científico, e também no campo burocrático, especialmente no acesso aos recursos. (LEITE et al., 1999, p. 47).

A terceira característica diz respeito aos sujeitos durante a pesquisa: os pesquisadores e os pesquisados. Como afirma González Rey (2002, p. 55):

Só a presença do pesquisador na situação interativa que toda pesquisa implica representar um elemento no sentido que afeta de múltiplas formas o envolvimento do sujeito pesquisado com a pesquisa (Grifos meus).

Esta afirmação do autor deixa claro que a construção do sujeito é um processo complexo e implica atuação ativa e dialógica por parte do pesquisador, e o pesquisado é "reconhecido pela sua singularidade como responsável pela qualidade de sua expressão relacionada com a qualidade de seu vínculo com o pesquisador" (G O NZALEZ REY, 2002, p. 57). Isso fortalece o papel do pesquisador e dos pesquisados como sujeitos participantes, não só na situação interativa, mas também na produção teórica. Portanto, os pesquisadores e suas relações com os sujeitos pesquisados são os principais protagonistas do processo investigativo.

A quarta característica está fundada na ideia de rede que se constrói ao longo do processo investigativo, buscando fortalecer o princípio da coerência

Rev. Diálogo Educ., Curitiba, v. 9, n. 26, p. 47-59, jan./ abr. 2009 
entre questões norteadoras, objetivos, procedimentos metodológicos e concepção de conhecimento. 0 êxito ou o fracasso, o sucesso ou as fragilidades das atividades do grupo dependem - em grande parte - de como enfrentam juntos os conflitos, as tensões e as contradições da prática investigativa. Para tanto, há necessidade de sistematizações periódicas por meio de reuniões técnicas e de estudos, tendo como referência as experiências já realizadas e levando em consideração os âmbitos epistemológicos e metodológicos.

Julgo necessário apresentar duas modalidades de pesquisa interinstitucional para compreender a complexidade da pesquisa em parceria.

A primeira modalidade, o foco e o design da pesquisa giram em torno de um tema maior de interesse dos grupos. D essa forma, há uma área de interesse comum, uma questão norteadora que irá orientar o desenrolar de todo o processo. A questão norteadora e sua problematização constituem o ponto crucial, do qual depende o bom andamento da pesquisa. Nessa perspectiva, todo o processo de pesquisa - definição e delimitação do problema, escolha da metodologia, coleta, análise e interpretação de dados, bem como a construção da base teórica - é decidido e assumido coletivamente pelos pesquisadores.

A elaboração do relatório final é também compartilhada, dando origem a um documento único. As quatro últimas experiências vividas e citadas na introdução deste texto são exemplos dessa primeira modalidade que parte de um projeto construído e assumido coletivamente e desenvolvido simultaneamente em cada instituição. Isto implica trocas de experiência, encontros técnicos para estudos e encaminhamentos.

A segunda modalidade refere-se à pesquisa em grupos com uma temática central, geralmente um tema maior de interesse de seus membros, mas com projetos com focos distintos. 0 importante a destacar-se é que, apesar de projetos diferentes, essas pesquisas relacionam-se com 0 tema maior, podem ter pontos comuns como a revisão de literatura, procedimentos e instrumentos metodológicos. É preciso que haja consonância entre a concepção de educação e de pesquisa, coerente com a de conhecimento ea de metodologia. Naprimeira pesquisa interinstitucional, citada anteriormente, a temática era a mesma; entretanto, cada instituição envolvida estudou casos inovadores diversificados, utilizando o mesmo referencial teórico baseado em Boaventura Sousa Santos. 0 produto final deu origem a quatro relatórios de pesquisa sobreinovações no ensinar e aprender na universidade. A pesar das distâncias territoriais (Porto Alegre, Pelotas, Brasília e Buenos Aires), os quatro grupos de investigação realizaram vários encontros para discussão de resultados parciais, aprofundamento teórico, troca de experiências e tomada de decisões relativas aos encaminhamentos teórico-metodológicos e técnicos.

Rev. D iálogo Educ., Curitiba, v. 9, n. 26, p. 47-59, jan./ abr. 2009 
VEIGA, I. P. A.

\section{0 que ficou de tudo isso?}

Entre as lições aprendidas nessas experiências com pesquisas interinstitucionais, ressalto alguns pontos facilitadores e outros, dificultadores. Foi possível compreender a importância de saber conviver em grupo, mas também foi possivel aprender a ser tolerante e paciente diante das dificuldades.

A presento, a seguir, a síntese provisória sobre a rica experiência de pesquisar em parceria, elencando primeiramente os pontos facilitadores:

- a participação é livre e os envolvidos procuram seu desenvolvimento profissional. É nesse processo de constante busca de liberdade do ser humano junto com os outros, na perspectiva de singularidade, que se realiza a construção coletiva;

- a confiança, o respeito mútuo, a reciprocidade afetiva, a solidariedade são necessários para a concretização da parceria e do compartilhamento. Isto significa que a dimensão afetiva está ligada à dimensão cognitiva do processo investigativo;

- todos os participantes da pesquisa experientes e iniciantes (alunos de iniciação científica, mestrandos, doutorandos, docentes novatos) passam pelo processo de apoio recíproco, unindo esforços em torno de um projeto comum;

- a abertura às inovações permite aceitar os novos caminhos investigativos com confiança;

- todos os participantes da pesquisa são protagonistas e não meros auxiliares. São protagonistas que ensinam os outros, que aprendem e produzem conhecimentos. Há articulação entre 0 individual e 0 coletivo, o que implica a valorização das diferenças como constitutivo do processo de construção de parceria e do coletivo;

- os protagonistas compartilham objetivos comuns, assumem responsabilidades, comprometem-se com as tarefas acadêmicas necessárias ao desenvolvimento da pesquisa em suas instituições. 0 poder é também compartilhado. A tomada de decisões é orientada pelas indagações centrais de como e para que se decide;

- a comunicação entre os grupos interinstitucionais é planejada e realizada por meio dos encontros e reuniões técnicas presenciais e por meios eletrônicos para troca de materiais escritos produzidos, tais como: textos do referencial teórico, artigos elaborados para apresentação em eventos científicos nacionais e internacionais, instrumentos de coleta de dados, cronogramas de eventos, síntese das atividades desenvolvidas, encaminhamento

Rev. Diálogo Educ., Curitiba, v. 9, n. 26, p. 47-59, jan./ abr. 2009 
de propostas, mensagens de confraternizações, entre outros. Isso implica a necessidade de transparência nas relações e na circulação da produção científica para todos os que estão participando do processo investigativo.

Se, de um lado, as experiências vividas deixam transparecer pontos facilitadores de pesquisa, de outro, têm mostrado que o processo, além de complexo, é permeado por fragilidades que podem ser agrupadas nos seguintes itens, a seguir:

- presença de conflitos e tensões decorrentes das relações de poder entre os grupos interinstitucionais e os participantes entre si;

- não-cumprimento das tarefas acadêmicas dentro dos prazos individuais e coletivos, previamente negociados, ocasionando atrasos na entrega dos produtos e muitas vezes sobrecarregando pesquisadores que assumem as tarefas que deveriam ser realizadas por outros participantes;

- falta de compromisso com a revisão de literatura, tendo em vista a não- participação das reuniões técnicas e de estudos, provocando limitações teórico-metodológicas;

- falta de entendimento do que é realmente uma pesquisa em parceria e interinstitucional;

- desconfiança, por parte de alguns, gerando incompreensões que afetam as relações interpessoais dos grupos;

- não-priorização da pesquisa como atividade acadêmica, acarretando a falta de tempo para dedicação ao projeto de investigação;

- pesquisador que sabe ouvir, mas não fala, é apático, não contribui para o aprofundamento das discussões. D eixa transparecer um ar desinteressado, desligado e nos momentos de tensões e conflitos apela para o lado emocional da conciliação. Sua contribuição não se dá pela dimensão formativa. Esta fica para depois, em suas reflexões individuais. No grupo, é solitário. Essa é uma forma invisível de fortalecer as relações de poder;

- por outro lado, pesquisador que não escuta, não sabe ouvir. D omina o grupo pela fala. Freire chama a atenção ao dizer que "[...] não é falando aos outros de cima para baixo, sobretudo, como se fôssemos portadores de verdade a ser transmitida aos demais que aprendemos a escutar" (FREIRE, 1999, p. 27). (G rifo do autor).

Rev. D iálogo Educ., Curitiba, v. 9, n. 26, p. 47-59, jan./ abr. 2009 
Além dessas fragilidades, os pesquisadores enfrentam muitos desafios. Um dos principais desafios da pesquisa interinstitucional é 0 estabelecimento dos vínculos entre os pesquisadores das diferentes universidades.

É importante deixar claro que, sem a conquista da relação de parceria e o compromisso ético dos pesquisadores, não é possível desenvolver a pesquisa interinstitucional. 0 real e fundamentalmente necessário é que o grupo de pesquisa deve ser flexível, estar permanentemente aberto e preparado para rever acordos, acertos e encaminhamentos decididos coletivamente.

Um outro desafio crucial no desenvolvimento de projeto de pesquisa de cunho interinstitucional é a constituição dos grupos de trabalho. Vale salientar quatro pontos básicos para a constituição do grupo:

- identificação com os integrantes do grupo, envolvendo interesses comuns, elos afetivos e profissionais;

- vontade de querer trabalhar junto e em conexão com as linhas de pesquisa;

- possibilidade de compartilhar problemas, experiências e objetivos comuns;

- interesse em realizar o desenvolvimento profissional de forma voluntária.

São muitos os desafios que surgem à medida que enveredamos pelo processo investigativo com a intenção de inová-lo. Uma das características desses desafios, apontada por González Rey (2002, p. 181) "[...] é a maneira como eles implicam de forma simultânea a reflexão teórica, epistemológica e metodológica." E para enfrentar esse desafio torna-se imprescindível apostar na capacidade de refletir e agir dos investigadores interinstitucionais. Nessa perspectiva, a relação entre a pesquisa e a ação docente não é uma relação entre uma teoria e uma prática, mas uma relação entre protagonistas: docentes-investigadores e alunos iniciantes na atividade de pesquisa.

\section{REFERÊNCIAS}

D EMO, P. E ducar pela pesquisa. Campinas: Autores A ssociados, 1996.

FERREIRA, A. B. H. N ovo Aurélio século XXI: o dicionário da língua portuguesa. 3. ed. Rio de Janeiro: Nova Fronteira, 1999.

FREIRE, P. Pedagogia da autonomia: saberes necessários à prática educativa. 11. ed. São Paulo: Paz e Terra, 1999.

Rev. Diálogo Educ., Curitiba, v. 9, n. 26, p. 47-59, jan./ abr. 2009 
GONZÁLEZ REY, F. L. Pesquisa qualitativa em psicologia: caminhos e desafios. São Paulo: Pioneira Thomson Learning, 2002.

HOUAISS, A.; VILLAR, M. S. Dicionário Houaiss da língua portuguesa. Rio de Janeiro: O bjetiva, 2001.

LEITE, D. et al. Inovação na universidade: a pesquisa em parceria. Revista Interface, Comunicação, Saude, Educação, v. 3, n. 4, p. 37-52, 1999. LÉVY, P. A inteligência coletiva: por uma antropologia do ciberespaço. 2. ed. São Paulo: Loyola, 1999.

OLIVEIRA, J. B. A. O rganização da universidade para a pesquisa. In: SCHWARTZMAN, M.; CASTRO, C. (O rg.). Pesquisa universitária em questão. São Paulo: Ícone, 1986.

SANTOS, B. S. Introdução a uma ciência pós-moderna. Rio de Janeiro: G raal, 1989.

SANTOS, B. S. Pela mão de Alice: 0 social e o político na pósmodernidade. Porto: Afornamento, 1994.

TOURAINE, A. Crítica à modernidade. 6. ed. Petrópolis, RJ: Vozes, 1999.

Recebido: 25/ 09/ 2008

Received: 09/ 25/ 2008

Aprovado: 12/ 11/ 2008

A pproved: $11 / 12 / 2008$

Rev. D iálogo Educ., Curitiba, v. 9, n. 26, p. 47-59, jan./ abr. 2009 